\title{
RARE CASE OF CELIAC TRUNK AND SMA THROMBOSIS PRESENTING AS AN ISOLATED GANGRENOUS CHOLECYSTITIS: A SURGICAL SURPRISE
}

\author{
Rajiv Jain ${ }^{1}$, Kiran Somani2, Kolla Venkatesh ${ }^{3}$, Abhishek Kansal ${ }^{4}$, Rajesh Sharma ${ }^{5}$ \\ ${ }_{1}^{1}$ Associate Professor, Department of Surgery, Sri Aurobindo Medical College \& PG Institute, Indore. \\ 2Professor, Department of Surgery, Sri Aurobindo Medical College \& PG Institute, Indore. \\ ${ }^{3}$ Resident, Department of Surgery, Sri Aurobindo Medical College \& PG Institute, Indore \\ ${ }^{4}$ Assistant Professor, Department of Surgery, Sri Aurobindo Medical College \& PG Institute, Indore. \\ 5 Professor, Department of Surgery, Sri Aurobindo Medical College \& PG Institute, Indore.
}

\begin{abstract}
Mesenteric vascular ischemia leads to gangrenous changes in the intestine and prognosis is very poor even after best surgical and medical care. Stenosis of celiac and superior mesenteric artery leads to patchy or diffuse involvement of small and large intestine. But, gangrene involving gall bladder with sparing of bowel and viscera, in the setting of mesenteric ischemia, has never been seen or reported.

CASE REPORT: We report a case of 45 year male presenting with isolated gangrenous cholecytitis which is quite a rare entity in celiac and SMA thrombosis.

CONCLUSION: This is the first case ever reported in which celiac trunk and SMA thrombosis is manifested solely as gangrenous cholecystitis, and the condition was treated successfully by laparoscopic surgery.
\end{abstract}

KEYWORDS: Gangrenous Cholecystitis, Celiac Trunk Thrombosis, SMA Thrombosis, Laparoscopy.

HOW TO CITE THIS ARTICLE: Rajiv Jain, Kiran Somani, Kolla Venkatesh, Abhishek Kansal, Rajesh Sharma. "Rare Case of Celiac Trunk and SMA Thrombosis Presenting as an Isolated Gangrenous Cholecystitis: A Surgical Surprise". Journal of Evolution of Medical and Dental Sciences 2015; Vol. 4, Issue 91, November 12; Page: 15697-15699, D0I: 10.14260/jemds/2015/2260.

INTRODUCTION: The majority of the blood supply of the gastrointestinal tract is provided by the anterior branches of the abdominal aorta: celiac trunk and superior mesenteric artery. Thrombosis of these major arteries can lead to devastating effects on the blood supply of abdominal organs including ischemia of the liver, spleen infarction and necrosis of the stomach, duodenum, small bowel and large intestine (From the caecum to the first third of transverse colon).

Celiac \& SMA thrombosis leading to gangrene of the bowel as well as gangrenous cholecystitis have been reported in the literature. But occurrence of isolated gangrene of gall bladder with sparing of bowel have never been reported anywhere in literature.

Here, we are reporting a rare case of celiac trunk and SMA thrombosis with anomalous origin of right hepatic artery from SMA presenting as isolated gangrenous cholecystitis with sparing of rest of abdominal viscera.

CASE REPORT: A 45 year old male presented in emergency department with sudden onset severe agonizing pain over right side of upper abdomen since 2 days. He had chronic dull aching pain and dyspepsia since 12 months and the intensity of pain had increased suddenly since 2 days. This pain was associated with multiple episodes of bilious vomiting and high grade fever and decreased urinary output. He was a chronic Bidi smoker and had undergone right lumbar sympathectomy 5 years back for Right lower limb PVD.

Financial or Other, Competing Interest: None.

Submission 21-10-2015, Peer Review 22-10-2015,

Acceptance 02-11-2015, Published 11-11-2015.

Corresponding Author:

Dr. Rajiv Jain

27, Anand Bagichi, Agrawal Nagar,

Indore-452001, Madhya Pradesh.

E-mail: drrajivjain16@yahoo.com

DOI:10.14260/jemds/2015/2260.
There was no other significant medical or surgical history. On presentation, the patient was febrile, dehydrated and sick looking. He had tachycardia [Pulse 120/min] and mild hypotension [BP 100/70 mmHg]. On abdominal examination, there was severe tenderness in right hypochondrium and Murphy's sign was positive. There was leucocytosis [15,500/cumm] and Neutrophillia [90\%] with normal alkaline phosphatase and amylase levels. Renal and Liver functions were within normal limits. Plain abdominal radiograph was normal.

Ultrasonography showed gangrenous gall bladder with perforation at the fundus of gall bladder with mild pericholecystic collection.

After adequate fluid resuscitation, urgent Laparoscopy was done. Intra operative findings were gangrenous gall bladder with purulent foul smelling pericholecystic collection. The entire gall bladder was gangrenous and sloughed out with perforation at the fundus of gall bladder. Calot's triangle was dissected and cystic duct and artery were isolated and there was no appreciable pulsation in the cystic artery. The duct and artery were clipped under vision. The visualized parts of liver and small and large bowel were apparently healthy with no sign of ischemia or necrosis. Postoperative recovery was uneventful.

To evaluate the cause of gall bladder gangrene, CT angiography of abdominal vessels was done. Surprisingly, the CT angiography revealed Focal Complete occlusion (100\%) seen at the celiac artery origin. And also at the proximal SMA, with distal recanalisation and collateral flow in its mid and distal segments. Special note is made on anomalous origin of right hepatic artery arising from the SMA with thrombus at origin and patent distal flow. Distal recanalisation and collateral flow was also seen in the hepatic artery proper and proximal splenic artery. 
In view of the above findings, the patient was, later on, sent to the vascular surgery centre for the definitive management of mesenteric vascular thrombosis.

This unique case is reported here because it was a rare case in which isolated gangrene of the gall bladder was a presenting feature of celiac trunk and SMA thrombosis and striking findings in the CT angiography.

DISCUSSION: Thrombosis of the celiac artery trunk is a rare cause of acute abdominal pain. This condition has important wide-ranging clinical implications because it compromises the blood supply of a large portion of the gastrointestinal tract and it may put at severe risk most of the abdominal viscera.[1] Thrombosis of the celiac artery carries a high mortality and morbidity when the diagnoses and treatment are delayed.[2]

Atherosclerosis, Behcet disease, thrombocytosis, protein $\mathrm{S}$, protein $\mathrm{C}$, antithrombin III deficiency, and malignancies which increase thrombotic tendency can be counted among the major etiologic factors of acute mesenteric ischemia.[3] The prognosis after mesenteric arterial embolism is better than that after arterial thrombosis or non-occlusive ischemia. [3]

In patients with persistent celiac flow abnormalities noted on duplex ultrasound or postoperative imaging, celiac angioplasty and stenting are advocated. If this option is not available or does not relieve symptoms, vascular reconstruction should be employed.[4] Mesenteric bypass surgery is a treatment option with better long-term results for mesenteric ischemia.[2]

Gangrenous acute cholecystitis is an uncommon form of cholecystitis, which if undiagnosed, is rapidly fatal. The incidence varies from $2 \%$ to $30 \%$ in most surgical series of acute cholecystitis.[5] The clinical diagnosis can be extremely challenging as the differentiation from acute cholecystitis may be very difficult pre-operatively as laboratory and imaging results may be non-specific.[6]

The initial investigation is sonography with Doppler color flow imaging. This will identify those acutely ill patients with gall bladder focal perfusion defects, as well as those with the sonographic signs of cholecystitis.[7] However, CT can play an important role in evaluation of these patients if sonography is inconclusive.[8]

There is a controversy regarding the best surgical approach to Gangrenous Cholecystitis with some authors, such as Eldar et al.[9] recommending open cholecystectomy. In contrast, Hunt and Chu.[5] indicated that laparoscopic cholecystectomy can be used relatively safely and successfully in patients with gangrenous cholecystitis, reporting a success rate of $91 \%$ without increased morbidity and no mortality.

In our case, the diagnosis was Gangrenous Cholecystitis which was dealt successfully by Laparoscopic Cholecystectomy. We had started with laparoscopy keeping a low threshold for conversion in case of difficulty. But, we were able to successfully complete it without conversion.

Generally, acute mesenteric ischemia is due to an impaired blood supply to the intestine caused by thromboembolic phenomena. Damage to the affected bowel portion may range from reversible ischemia to transmural infarction with necrosis and perforation. Injury severity is inversely proportional to the mesenteric blood flow and is influenced by the number of vessels involved, systemic mean blood pressure, duration of ischemia, and collateral circulation.

In our case, the involvement of only gall bladder may be due to embolism to the cystic artery alone in the setting of compensated chronic mesenteric ischemia.

Though there was presence of critical occlusion of celiac trunk and SMA, the formation of collateral circulation had led to sparing of bowel and other abdominal organs.

Thus, our was the rare case of gangrene of gall bladder presenting as a isolated finding of a generalized mesenteric vascular disorder, and it was managed successfully by laparoscopic technique.

CONCLUSION: Acute thromboembolic occlusion of the celiac trunk and superior mesenteric artery (SMA) is a condition with a serious prognosis.

In conclusion, the present clinical report describes a condition of thrombosis involving the celiac axis and SMA with the anomalous origin of Right Hepatic artery, manifesting solely as gangrene of the gall bladder with sparing of bowel and other viscera, and its successful Laparoscopic management.

\section{REFERENCES:}

1. Federico Lovisetto, Gianbattista Finocchiaro De Lorenzi, Piera Stancampiano, Carmen Corradini, Fabio De Cesare, OrazioGeraci, Mario Manzi, Francesco Arceci. Thrombosis of celiacomesenteric trunk: Report of a case. World J Gastroenterol 2012 August 7; 18(29): 3917-3920.

2. Hasan Attila Keskin, Fahri Yetisir, Huseyin Bayram, et al., "Celiac Artery Thrombosis and Superior Mesenteric Artery Stenoses with Essential Thrombocythemia: A Case Report," Case Reports in Medicine, vol. 2012, Article ID 741653, 3 pages, 2012.

3. Schoots, I. G., Koffeman, G. I., Legemate, D. A., Levi, M. and van Gulik, T. M. (2004), Systematic review of survival after acute mesenteric ischaemia according to disease aetiology. Br J Surg, 91: 17-27.

4. Duffy AJ, Panait L, Eisenberg D, Bell RL, Roberts KE, Sumpio B.Management of median arcuate ligament syndrome: a new paradigm. Ann Vasc Surg. 2009 NovDec; 23(6):778-84.

5. Hunt DR, Chu FC. Gangrenous cholecystitis in the laparoscopic era. Aust N Z J Surg. 2000; 70:428-30.

6. Bennett GL, Rusinek H, Lisi V, Israel GM, Krinsky GA, Slywotzky CM, et al. CT findings in acute gangrenous cholecystitis. AJR Am J Roentgenol. 2002; 178:275-81.

7. Peter Corr. Sonography of gangrenous cholecystitis. J Emerg Trauma Shock. 2012 Jan-Mar; 5(1): 82-83.

8. S Chaudhry, R Hussain, Rajaganeshan Rajasundaram, D Corles. Gangrenous cholecystitis in an asymptomatic patient found during an elective laparoscopic cholecystectomy: a case report. Journal of Medical Case Reports 2011, 5:199.

9. Bingener J, Stefanidis D, Richards ML, Schwesinger WH, Sirinek KR: Early conversion for gangrenous cholecystitis: impact on outcome. Surg Endoscopy 2005, 19(8):11391141. 


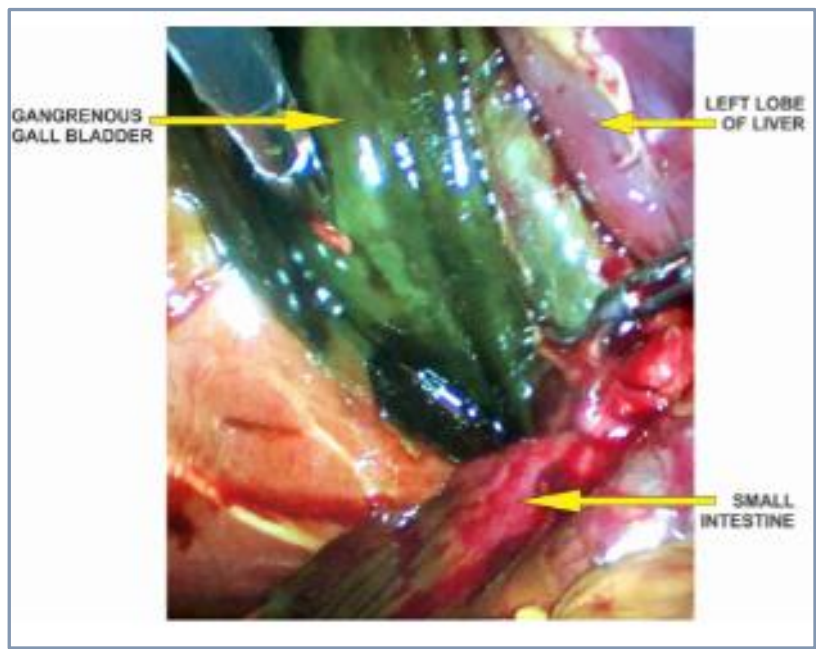

Fig. 1: Showing the gangrenous gall bladder

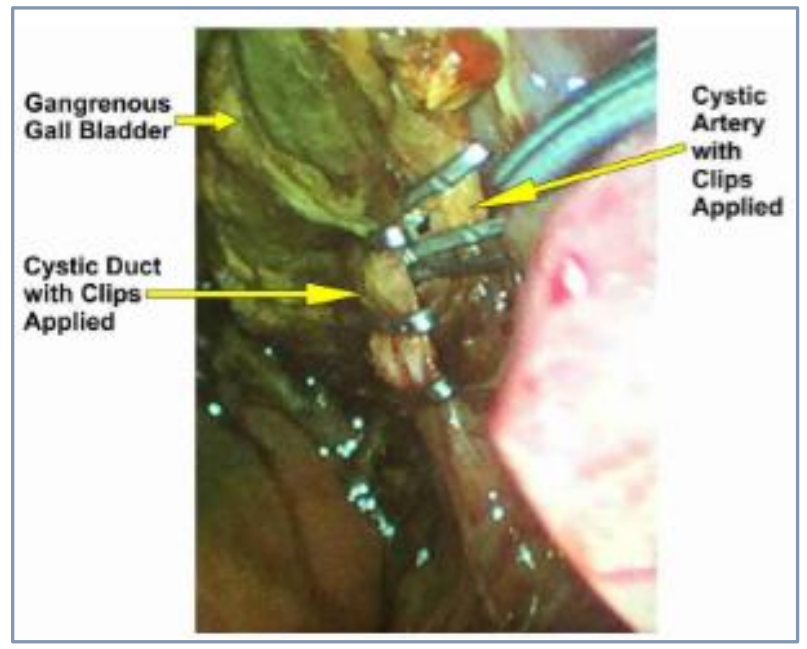

Fig. 2: Photo of gangrenous gall bladder with calot's triangle dissected and clips applied

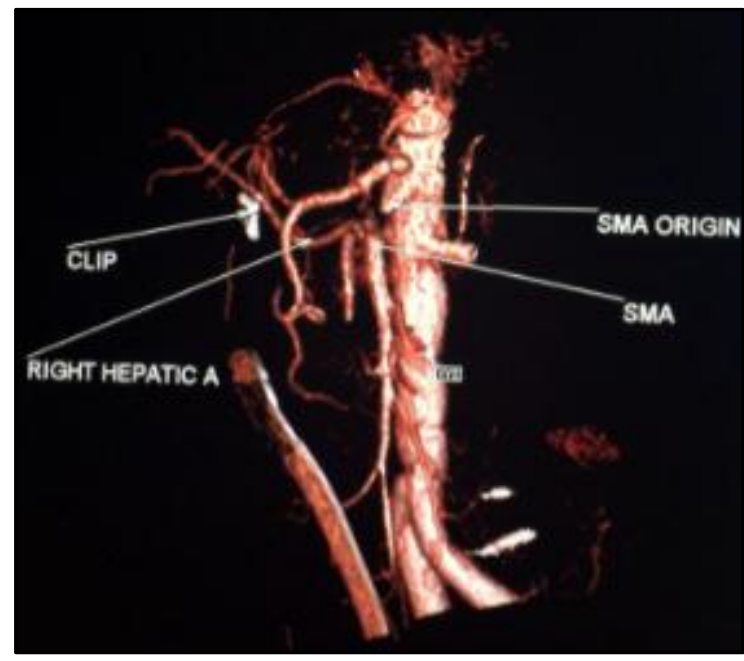

Fig. 3: CT Angiography picture showing anomalous origin of right Hepatic artery from SMA

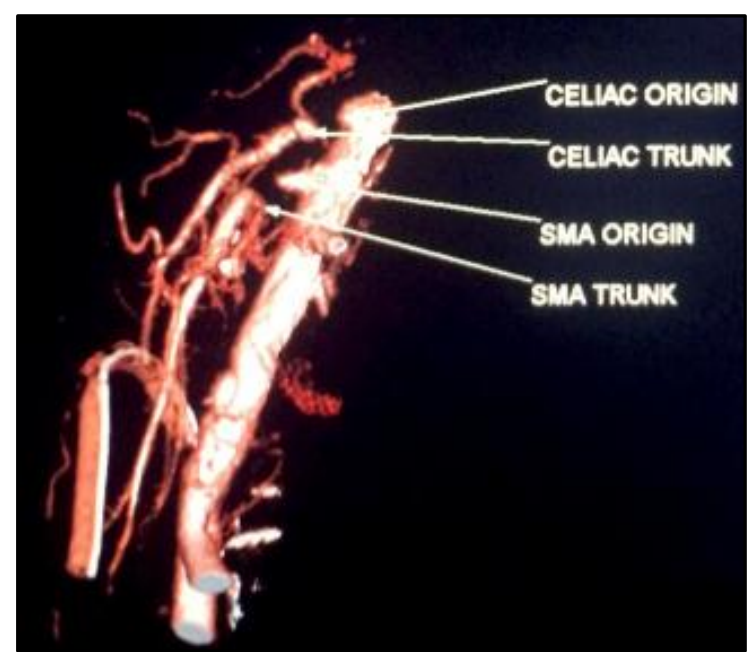

Fig. 4: CT Angiography picture showing thrombosis of Celiac Trunk and SMA 